\title{
History of the Microwave-Tube Art at Tohoku University
}

\author{
Kuniyoshi $\mathrm{YOKOO}^{\dagger}$, Member and Koji MIZUNO $^{\dagger \text { a) }}$, Fellow
}

SUMMARY In 1919 the Department of Electrical Engineering (EE) was established in Tohoku University (at that time, Tohoku Imperial University). In this Department a growing tendency towards research featured in science and technology for electrical communication. Great efforts made in these fields produced pioneering studies such as those of the Yagi-Uda antenna and slotted-anode type magnetrons in the late 1920s. The purpose of this article is to introduce the history of development of microwave electron-tube at Tohoku University, which was started with the Okabe's magnetron.

key words: microwave tubes, slotted-anode magnetron, Peniotron, Ledatron, Tohoku University

\section{Introduction}

Professor H. Yagi, one of the founders of the EE Department, Tohoku Imperial University, made a guideline of the Department to be research of electrical communication, or electronics, though at that time main stream of electrical engineering was power engineering. Other guides to research of the EE Department were and have been "Toward Higher Frequency" and "Making Experiment Devices by Oneself".

In the 1920s main active device in the area of electrical communication was electron tube. In 1927 Dr. Kinjiro Okabe in the Department found RF oscillation in magnetrons when he conducted laboratory experiments. Through studying this oscillation, he succeeded in generating oscillation at the cm-region, the shortest wavelength oscillation in the world at that time.

After that, in the EE Department in Tohoku University, several electron tubes such as Pniotron, double-ridge waveguide Peniotron, TE11 Peniotron, and Ledatron, for the generation of microwaves and Terahertz waves have been proposed and developed.

\section{Magnetron-Related Development}

\subsection{Tables and Figures}

In 1927 while Dr. Okabe conducted laboratory experiments on magnetron he found the characteristics shown in Fig. 1, which were experimentally-obtained curves of anode-current vs. magnetic field. He was interested in the dips of several curves, leading to finding of RF oscillation. In 1929 he obtained $5.6 \mathrm{~cm}(5.4 \mathrm{GHz})$ oscillation with

\footnotetext{
Manuscript received April 3, 2015.

${ }^{\dagger}$ The authors are with Research Institute of Electrical Communication, Tohoku University, Sendai-shi, 980-8577 Japan.

a)E-mail: koji@ riec.tohoku.ac.jp

DOI: 10.1587/transele.E98.C.613
}

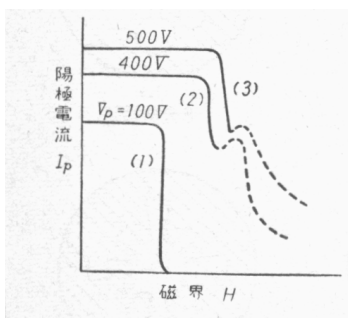

(a)

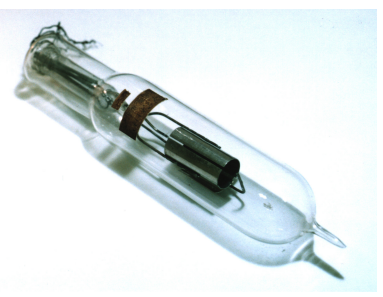

(b)
Fig. 1 (a) The anode-current Ip vs. magnetic field $\mathrm{H}$ with which Dr. Okabe had the idea of RF oscillation of magnetron in 1927 [2] . (b) Photo of Okabe's magnetron.

$$
\text { サブミリ波徃生, 新じ電子管（Peniotron） }
$$

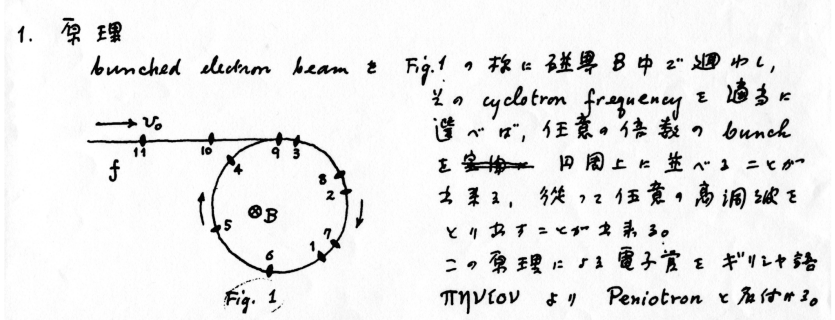

Fig. 2 Professor Koike's note on his Peniotron. The title of this note is "A new electron tube (Peniotron) for the generation of submillimeter waves" in Japanese.

slotted-anode type magnetron [1]. This success triggered a vast amount of research in the 1930's on magnetrons in the world. After development for radars, magnetrons are now quite widely used for energy source of microwave ovens.

\section{Peniotron}

In 1957 Professor Y. Koike proposed a new electron tube using cyclotron motion of electrons. He named the tube "Peniotron" after Greek word "penio" which means spool. The title of his note to describe the idea was "A new electron tube -Peniotron- for generating submillimeter-waves". It is noteworthy that already in the late 1950s the word of "sumillimeter waves" was being used in Tohoku University.

This idea of Peniotron was taken over by Professor S. Ono and Peniotron has been developed by successors. In the Peniotron electrons in cyclotron motion interact with electromagnetic wave supported by waveguides. Professor K. Yamanouchi used double-ridge waveguide as Peniotron 


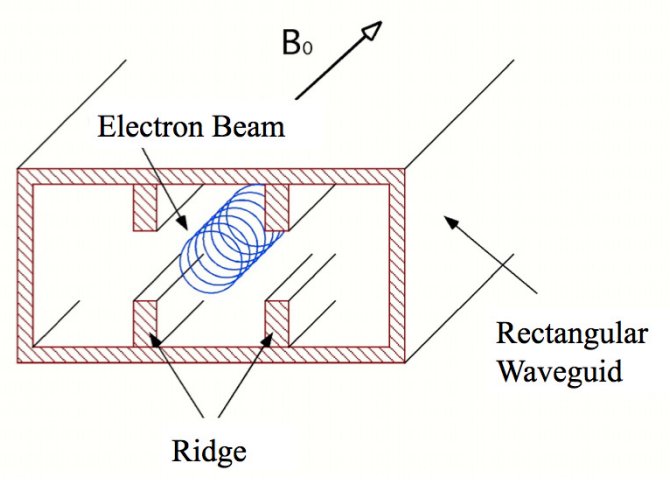

Fig. 3 Configuration of the double-ridge waveguide Peniotron.

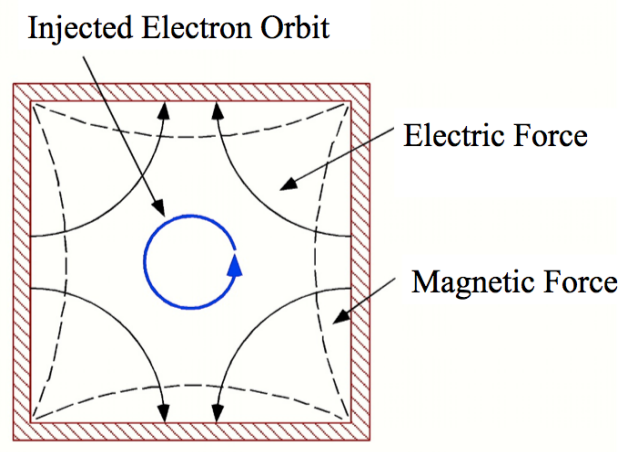

Fig. 4 Configuration of the TE 11- mode Peniotron.

interaction circuit (1963, [3]) and Professor K. Yokoo proposed TE11-mode rectangular and also circular waveguides (1985, [4]) as interaction circuits, resulting in extremely high-efficiency of 94\% obtained in 1998 [5]. Such high efficiency depends on shifting of all of electron orbit centers of the cyclotron motion to the deceleration electric field of electromagnetic wave in a waveguide resonator without electron bunching.

\section{Ledatron}

In 1964 Professor Ono proposed a new electron tube with an open cavity structure for the generation of submillimeter waves. In the tube, an electron beam interacts with a resonant mode of the Fabry-Perot resonator with a metallic grating (Fig. 5). This tube was named Ledatron after Leda, a mother of a twin in Greek mythology, since there were two different modes of interaction in the tube (1973, Professor K. Mizuno, [6]). The oscillation of the frequency of $300 \mathrm{GHz}$ has been obtained with Ledatron and it was the first electron device to combine technologies of the microwave region (microwave electron tube operation) and the optical region (open-type interferometer, resonator) [7]. The Ledatron is now introduced in several textbooks [8] for microwave/mm-wave engineers.

Professor Mizuno later applied this quasi-optical (open) structure to develop submillimeter-wave solid-state

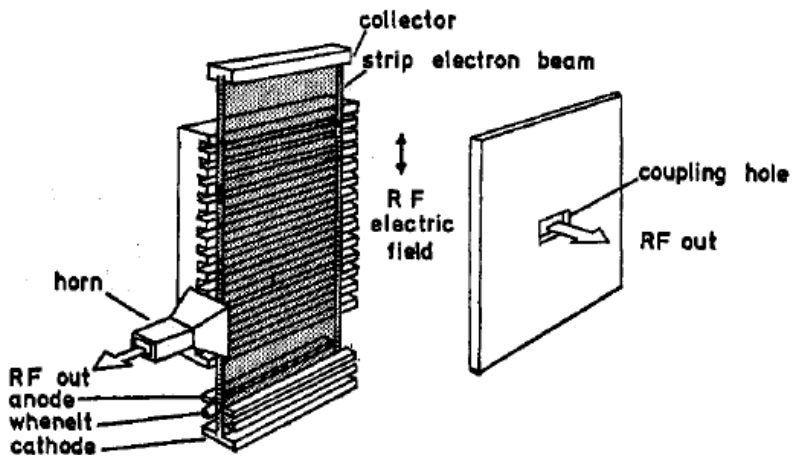

Fig. 5 Configuration of the Ledatron [7]. The first realization of combining technologies of the microwave region and the optical region.

devices, giving one of the guiding principle to develop practical $\mathrm{THz}$ device structure. The new structure has a plane substrate with quasi-optical dimensions of some 10 wavelengths, and several/many devices are mounted on the plane. When the devices are solid-state oscillators such as transistors and the plane forms a Fabry-Perot resonator with another mirror, the structure becomes a solid-state power combiner with improved spectrum purity [9]. As there are no high-power solid-state sources in the submillimeter-wave region, this structure is useful to obtain solid-state oscillators with practical power output in the region. When the devices are detectors, the structure forms imaging-arrays [10].

\section{University Machine Shop}

In its early days of the EE Deartment of Tohoku Imperial University there were already technicians for vacuum technologies and glasswork in the Department. Okabe magnetrons were made at the Department workshop according to his idea. It was not uncommon to have machine shops at that time in Japanese universities, however the facility of glasswork was unique. In 1950's there was a subject of "making of vacuum diodes and measurements of their I-V characteristics" for laboratory experiments for EE students there.

As to the development of Ledatron a milling machine in the Department machine shop was used to cut metallic gratings. The machine had an optical scale to position a work on a table with an accuracy of $+/-1$ micrometer. At the cutting the material of the grating (Cu-Ni-Si alloy) and cutting fluid were carefully chosen. Grooves with, e.g., the width of 50 micrometers, the depth of 200 micrometers and the pitch of 150 micrometers were cut on a grating of $30 \mathrm{X}$ $30 \mathrm{~mm}$-surface using the milling machine [11].

The above-mentioned electron tubes were all not only proposed in Tohoku University but also developed using experimental prototypes made at its university machine shop. It is a Tohoku tradition that researchers should make their own instruments. 


\section{Summary}

In its about 100-years history of the EE Department of Tohoku University several new microwave/mm-wave electron tubes with unique characteristics have been developed. This achievement may have been accomplished with some guiding principles existed in the Department, such as "Toward Higher Frequency", "Making Experiment Devices by Oneself", "Use of Cyclotron Motion of Electrons, and "Use of Quasi-optical Structure".

History of the development of electron tubes at Tohoku University shows proper guiding principles, or visions are quite important for research.

\section{References}

[1] K. Okabe, "On the Short-wave Limit of Magnetron Oscillations," Proc. IRE, vol.17, no.4, pp.652-659, April 1929.

[2] S. Uda, Musen-kogaku II, Maruzen, Tokyo, 1958 (in Japanese).

[3] K. Yamanouchi, S. Ono, and Y. Shibata, "Cyclotron fast wave tube : the double ridge travelling wave peniotron," Proc. 5th Int. Cong, on Microwave Tubes, pp.96-102, 1964.

[4] M. Razeghi, N. Sato, K. Yokoo, and S. Ono, "Modified peniotron using a TE 11 rectangular waveguide cavity," Int. J. Electronics, vol.59, no.5, pp.533-542, 1985.

[5] T. Ishihara, K. Sagae, N. Sato, H. Shimawaki, and K. Yokoo, "Highly Operation of Space Harmonic Peniotron at Cyclotron High Harmonics," IEEE Trans. Electron Devices, vol.ED-46, pp.798-802, April 1999.

[6] K. Mizuno, S. Ono, and Y. Shibata, "Two Different Mode Interactions in an Electron Tube with a Fabry-Perot Resonator-The Ledatron," IEEE Trans. Electron Devices, vol.ED-20, pp.749-752, Aug. 1973.

[7] K. Mizuno and S. Ono, Infrared and MillimeterWaves, vol.1, Academic Press, New York, 1979.

[8] P. Bharta and I.J. Bahl, Millimeter wave Engineering and Applications, John Wiley \& Sons, New York, USA, 1984.

[9] K. Mizuno, T. Ajikata, M. Hieda, and M. Nakayama, "Quasi-optical Resonator for Millimeter and Submillimeter Wave Solid-State Sources," Electron. Lett., vol.24, pp.792-793, Hune 1988.

[10] K. Mizuno, "Multi-Element Quasi-Optical Devices - a New Trend in Short Millimeter and Submillimeter Wave Electron Devices [Invited]," 5th Aust. Symp. on MM \& Sub-MM Waves, Adelaide, Aug. 1992.

[11] K. Mizuno, M. Ohuchi, S. Ono, Y. Shibata, and K. Kamiryo, "Craft milling of the grooved mirror for the Fabry-Perot resonator used in the submillimeter wave tube," THE RECORD OF ELECTRICAL AND COMMUNICATION ENGINEERING CONVERSATION, TOHOKU UNIVERSITY, vol.37, no.4, pp.398-403, Feb. 1969.

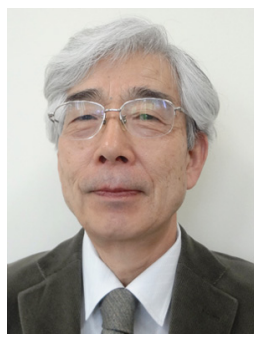

Kuniyoshi Yokoo received the B.S. degree in electronics engineering from Shizuoka University, Hamamatsu, Japan, in 1962, and the M.S. and Dr. Eng. degrees in electronics engineering from Tohoku University, Sendai, Japan, in 1968 , and 1974, respectively. He was a Research Associate in the Department of Electronics Engineering of Tohoku University from 1971 to 1983 and an Assistant Professor and a Professor in the Research Institute of Electrical Communication of Tohoku University from 1983 to 2003. Since 2003, he has been a Professor Emeritus of Tohoku University. He has been engaged in research work in the fields of microwave tubes, solid-state active devices, and vacuum nanoelectronics devices. Dr. Yokoo is a senior member of the IEEE and the Institute of Electronics, Information, and Communication Engineers of Japan and the Japan Society of Applied Physics.

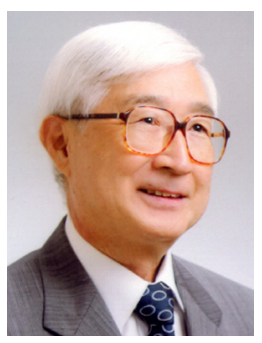

Koji Mizuno was graduated from the Department of Electronic Engineering, Tohoku University, Sendai, in 1963. He completed his Doctorate in Engineering in 1968. After being a research associate and an associate professor, he was appointed Professor (RIEC, Research Institute of Electrical Communication) at the same University in 1984. He was a visiting researcher at the University of London (Queen Mary College), London, in 1972, and at California Institute of Technology, Pasadena, in 1990. He concurrently served as a team leader at the Photodynamics Research Center, the Institute of Physical and Chemical Research (RIKEN), Sendai, from 1990-1998. In 2004 he was appointed Professor Emeritus of Tohoku University and also Research Professor of RIEC. During this time, he was involved in the research and development of devices and measuring instruments in the millimeter- and submillimeter-wave $(\mathrm{THz})$ band. He received the IEEE Fellow grade in 1993 (now LF), the Kenneth J. Button Medal in 1998, and the Minister Award of MEXT (Ministry of Education, Culture, Sports, Science and Technology, Japan) in 2003, and the Distinguished Educator Award of the IEEE Microwave Theory and Techniques Society in 2005. His hobbies are sailing and playing the flute. 